\title{
PENERAPAN ALGORITMA ANT COLONY OPTIMIZATION (ACO) \\ PADA JOB SHOP SCHEDULING PROBLEM (JSSP) DI PT. SIEMENS INDONESIA (CILEGON FACTORY)
}

\author{
Widyawati \\ Universitas Banten Jaya \\ Serang, Banten \\ widyawati@unbaja.ac.id
}

\begin{abstract}
Fabrication process is often disrupted by non-deterministic job, this create a problem in the Pre-Fabrication department schedule because often the manufacture of raw material for nondeterministic job should given priority. This problem also affected by the existing system which is not yet fully developed to solve the problem of optimize rescheduling master line (seen from total makespan time). Ant Colony Optimization (ACO) variant Ant System (AS) was proposed to solve Job Shop Scheduling Problem (JSSP) with the objective to propose the best schedule that give shortest makespan. The algorithm tested to perform scheduling of 5 projects (consist of 10 parts) as the initial job, and another 2 projects (consist of 4 parts) as the non-deterministic job. For the initial job, makespan was 287 days and after the arrival of non-deterministic job, makespan was 362 days compare with the actual manufacturing time (7 project consist of 14 parts) which is \pm 511 days.
\end{abstract}

Keywords: Ant Colony Optimization (ACO), Job Shop Scheduling Problem (JSSP), Makespan Time, Non-Deterministic, Scheduling, Re - Scheduling

\section{PENDAHULUAN}

PT. Siemens Indonesia Cilegon Factory (PTSI-CF) merupakan perusahaan yang bergerak dibidang fabrikasi komponen turbin dan produk industri logam presisi tinggi. Perusahaan tersebut berjalan berdasarkan konsep job by order (produk yang diproduksi atas surat pesanan pelanggan). Kendala yang seringkali dihadapi adalah adanya pekerjaan yang tidak bisa diramalkan (non-deterministic) sehingga membuat jadwal produksi yang telah direncanakan perlu dilakukan perubahan. Dan non deterministic menyebabkan waktu penyelesaian (makespan time) lebih panjang.

Ada tiga pendekatan untuk penjadwalan ulang, yaitu: dengan menjadwalkan kembali dari awal, melakukan perubahan terhadap jadwal saat perubahan terjadi, atau menunda beberapa operasi yang telah dikerjakan pada jadwal lama dan melakukan 
penjadwalan ulang terhadap sisa operasi yang belum dikerjakan. Penelitzian ini bertujuan untuk mencari penjadwalan dengan makespan time yang paling minimum menggunakan algoritma Ant Colony Optimization (ACO) berjenis Ant System (AS).

\section{Metode}

Metode penelitian ini dilakukan dengan beberapa tahap seperti studi literatur, pengumpulan data, pengolahan data, dan analisis hasil.

Diagram Alir, berikut ini merupakan tahapan yang dilakukan dalam penelitian:

A lgoritma A lternatif:

1. Classical Iterativel mprovement

2. Threshiold Algorithms, Tabu Search

3. Simulated a nneasing, Genetic algarith ms

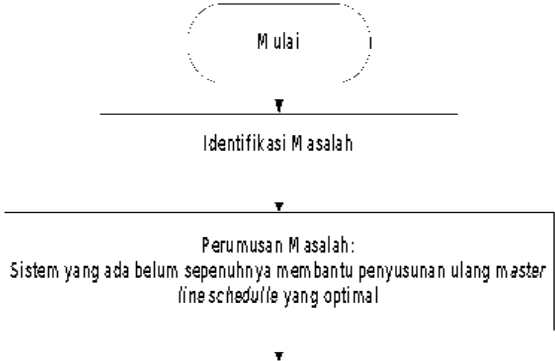

Tujuan Penelitian:

M endapatkan suatu sistem penjadwalan produksi yang lebih baik dengan meminim um kan total waktu pengerjaan seluruh job Iminimalisasi makespan time)

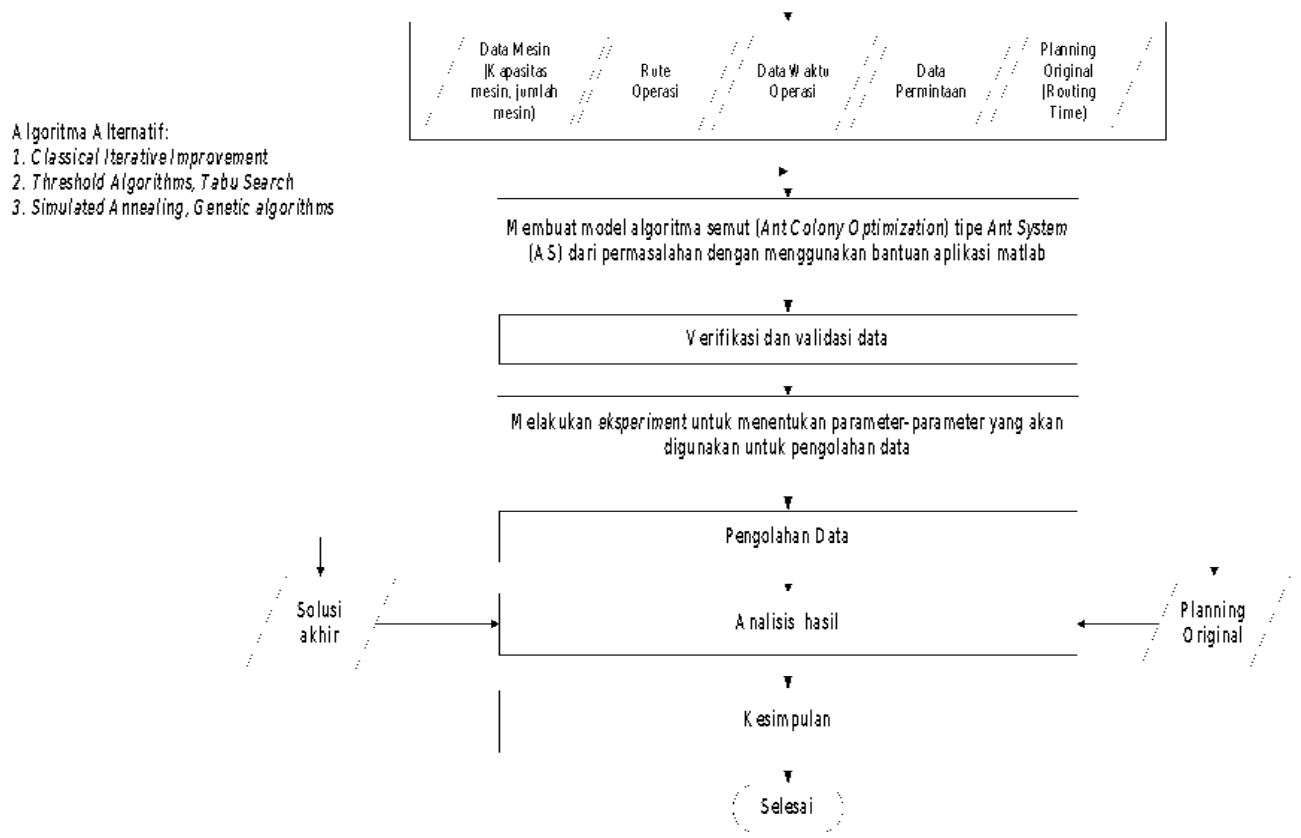

Gambar 1 Diagram Alir Penelitian 


\section{Pengumpulan Data}

Sumber data yang digunakan didalam penelitian ini merupakan data sekunder yang diperoleh dari sumber yang sudah ada yaitu berupa dokumen perusahaan. Data yang digunakan adalah data sekunder, yaitu berupa data jumlah project pada tahun 2015, rute project, dan waktu proses setiap project.

\section{Pengolahan Data}

Adapun teknik pengolahan data yang dilakukan yaitu dengan menerapkan algoritma Ant Colony Optimization (ACO) berjenis Ant System (AS). Berikut ini merupakan tahapan secara umum dalam melakukan proses pengolahan data:

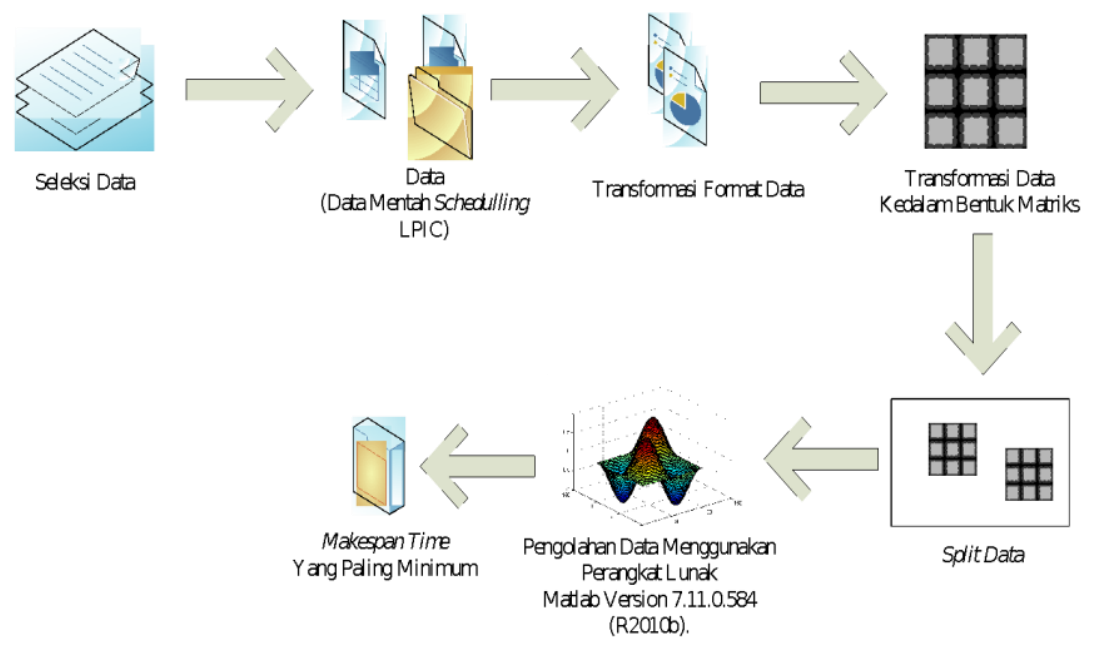

\section{Gambar 2 Tahapan Pengolahan Data}

\section{Metode Ant Colony Optimization}

Algoritma semut atau Ant Colony Optimization (ACO) merupakan algoritma pencarian berdasarkan probabilistik, di mana probabilistik yang digunakan merupakan probabilistik dengan bobot sehingga butir pencarian dengan bobot yang lebih besar akan berakibat memiliki kemungkinan terpilih lebih besar pula (Anamisa \& Djunaidy, 2014).

Model yang digunakan untuk menotasikan masalah penjadwalan jobshop pada n-job dan m-mesin adalah (Zukhri \& Alhakim, 2004):

$$
n / m / G / C \max
$$


Yang mana $\mathrm{n}$ mendefinisikan banyaknya job yang akan diproses, m menunjukkan banyaknya mesin yang dimiliki, $\mathrm{C}_{\max }$ merupakan minimum makespantime dari suatu produksi dan $\mathrm{G}$ berisikan aturan urutan proses mesin untuk setiap job dan waktu prosesnya. Proses mesin dimodelkan dalam bentuk matrik T, semisal untuk T dengan $\mathrm{n}=2$ dan $\mathrm{m}=3$ adalah sebagai berikut:

$T=\left[\begin{array}{lll}M 1 & M 2 & M 3 \\ M 4 & M 5 & M 6\end{array}\right]$

Sedangkan untuk merepresentasikan waktu proses setiap operasi dimodelkan dengan matrik P:

$P=\left[\begin{array}{ccc}t\left(O_{11}\right) & \cdots & t\left(O_{1 m}\right) \\ t\left(O_{21}\right) & \cdots & t\left(O_{2 m}\right) \\ \cdots & \cdots & \cdots \\ \cdots & \cdots & \cdots \\ t\left(O_{n 1}\right) & \cdots & t\left(O_{n m}\right)\end{array}\right]$

Untuk merepresentasikan permasalahan jobshop pada algoritma semut digunakan graph sebagai model yang akan mempermudah dalam pencarian minimum waktu penyelesaian. Model graph dari 2/3/G/Cmax job shop dapat digambarkan pada gambar 3 dibawah ini:

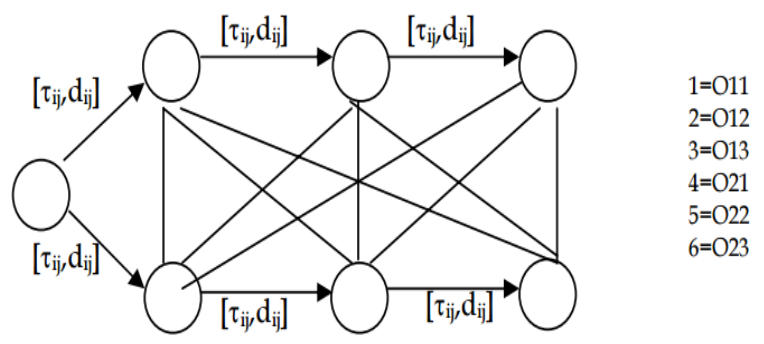

\section{Gambar 3 Representasi 2/3/G/Cmax job shoppada graph}

Setiap node dalam graph merupakan representasi dari job operasi pada matrik $\mathrm{T}$, jumlah node dirumuskan dengan:

Nodes $=(n * m)+1$ 
Sedangkan untuk banyaknya garis dinotasikan sebagai berikut:

Garis $=|O| *(|O|-1) 2+N$

$|O|=n * m$

Dalam graph diatas setiap node memiliki batasan node yang dapat dikunjungi karena terdapat beberapa garis satu arah maka suatu node tidak memiliki hak untuk melalui jalur yang berlawanan arah dengan tanda arah panah tersebut. Dengan demikian setiap operasi penentuan mesin harus terlebih dahulu memeriksa batasan mesin yang boleh dilalui.Selain itu pemilihan node tujuan yang layak dilalui difilter dengan batasan operasi yang harus terurut.Misalkan jika job 1 operasi ke-2 hanya boleh dipilih sebagai node tujuan jika job 1 operasi ke-1 telah dipilih atau dilalui oleh semut.

Berikut ini merupakan flowchart penerapan algoritma ACO:

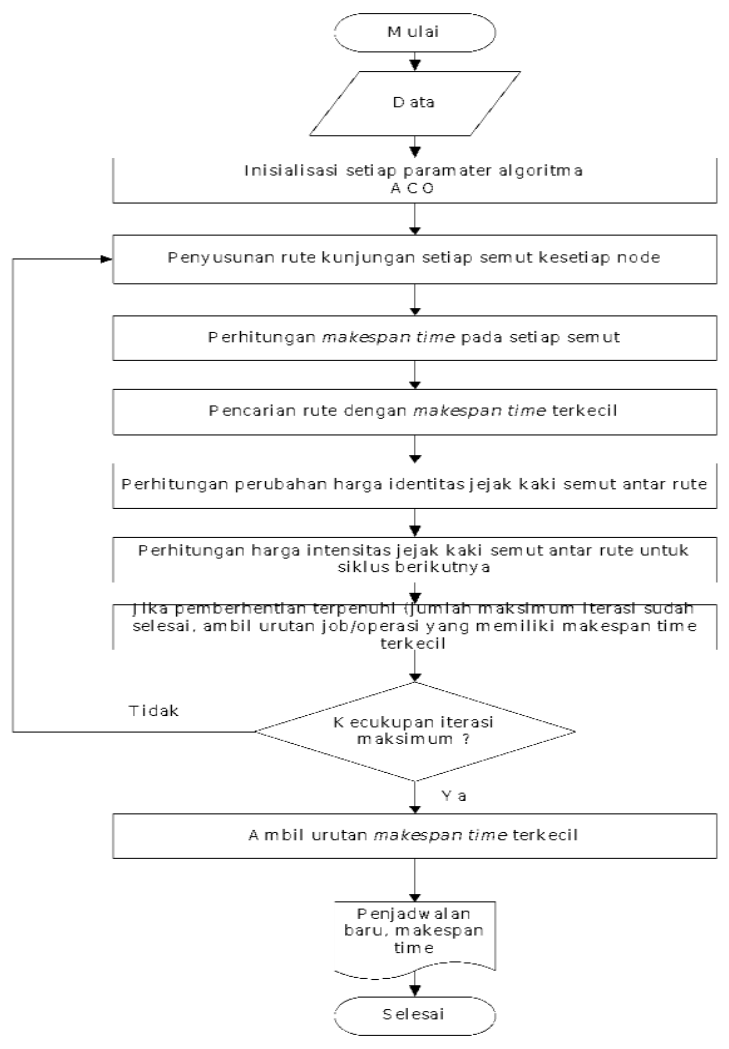

Gambar 4 Tahapan Pengolahan Data 


\section{Hasil dan Pembahasan}

Penelitian yang dilakukan dalam penerapan algoritma Ant Colony Optimization (ACO) untuk penyelesaian Job Shop Scheduling Problem(JSSP) di PT. Siemens Indonesia menggunakan bantuan perangkat lunak Matlab. Data yang digunakan merupakan hasil pengolahan terhadap data scheduling produk PT. Siemens Indonesia. Data ini menjelaskan mengenai Schedule bahan baku suatu project/job mulai masuk dan diproses di suatu mesin hingga selesai pada mesin tertentu di departemen PreFabrication (PF). Schedule tersebut diolah dari yang awalnya berbentuk monitoring board dirubah kedalam bentuk matriks sehingga mudah dalam proses penerapan reschedule menggunakan algoritma ACO dengan bantuan Matlab. Dari hasil pengolahan data didapatkan total waktu penyelesaian (makespan time) yang paling minimum.

\section{Seleksi Data}

Tahap awal dari perancangan penelitian ini adalah tahap seleksi data, yaitu pemilihan atribut yang nantinya dilakukan proses transformasi data dari data mentah kedalam bentuk tabel matriks untuk diolah ke tahap selanjutnya.

\begin{tabular}{|c|c|c|c|c|c|c|c|c|c|c|}
\hline No. & $\begin{array}{l}\text { Project } \\
\text { Name }\end{array}$ & $\begin{array}{c}\text { Type } \\
\text { Project }\end{array}$ & Komponen (Job) & Status P0 & Planning & $\begin{array}{c}\text { Flame } \\
\text { Cutting } \\
\text { (CNC+Sawin } \\
\text { g+Nanual } \\
\text { Cutting) }\end{array}$ & $\begin{array}{c}\text { Rolling } \\
\text { (Internal } \\
\& \\
\text { Eksternal) }\end{array}$ & $\begin{array}{c}\text { Machinin } \\
\text { g Small } \\
\text { Part }\end{array}$ & \begin{tabular}{|c|} 
Assy \\
Single \\
Part \\
(Weldingt \\
NDT)
\end{tabular} & $\begin{array}{c}\text { Assy Sub } \\
\text { Assy } \\
\text { (Welding+N } \\
\text { DT) }\end{array}$ \\
\hline \multirow{2}{*}{1} & \multirow{2}{*}{ LPIC 1} & \multirow{2}{*}{ TYPE E } & NNER CASING WELDING-UPPER PART & \multirow{2}{*}{ PO RELEASE } & \multirow{2}{*}{ 23-Feb-15 } & 3-Nov-14 & 13-Nov-14 & 14-Nov-14 & 26-Nov-14 & 6-Dec-14 \\
\hline & & & LP INNER CASING WELDING-LOWER PART & & & 13-Nov-14 & 25-Nov-14 & 26-Nov-14 & 6-Dec-14 & 17-Dec-14 \\
\hline \multirow{2}{*}{2} & \multirow{2}{*}{ LPIC 2} & \multirow{2}{*}{ TYPE F } & LP INNER CASING WELDING-UPPER PART & \multirow{2}{*}{ PO RELEASE } & \multirow{2}{*}{ 16-Mar-15 } & 25-Nov-14 & 4-Dec-14 & 5-Dec-14 & 17-Dec-14 & 1-Jan-15 \\
\hline & & & LP INNER CASING WELDING-LOWER PART & & & 4-Dec-14 & 16-Dec-14 & 17-Dec-14 & 1-Jan-15 & 10-Jan-15 \\
\hline \multirow{2}{*}{3} & \multirow{2}{*}{ LPIC 3} & \multirow{2}{*}{ TYPE A } & LP INNER CASING WELDING-UPPER PART & \multirow{2}{*}{ PO RELEASE } & \multirow{2}{*}{ 7-Apr-15 } & 16-Dec-14 & 30-Dec-14 & 31-Dec-14 & 10-Jan-15 & 22-Jan-15 \\
\hline & & & LP INNER CASING WELDING-LOWER PART & & & 30-Dec-14 & 9-Jan-15 & 10-Jan-15 & 22-Jan-15 & 31-Jan-15 \\
\hline \multirow{2}{*}{4} & \multirow{2}{*}{ LPIC 4} & \multirow{2}{*}{ TYPE F } & LP INNER CASING WELDING-UPPERPART & \multirow{2}{*}{$\begin{array}{c}\text { PO NOT } \\
\text { RELEASE }\end{array}$} & \multirow{2}{*}{ 28-Apr-15 } & 9-Jan-15 & 20-Jan-15 & 21-Jan-15 & 31-Jan-15 & 12-Feb-15 \\
\hline & & & LP INNER CASING WELDING-LOWER PART & & & 20-Jan-15 & 30-Jan-15 & 31-Jan-15 & 12-Feb-15 & 21-Feb-15 \\
\hline \multirow{2}{*}{5} & \multirow{2}{*}{ LPIC 5} & \multirow{2}{*}{ TYPE E } & LP INNER CASING WELDING-UPPER PART & \multirow{2}{*}{ PO RELEASE } & \multirow{2}{*}{ 21-May-15 } & 29-Jan-15 & 10-Feb-15 & 11-Feb-15 & 21-Feb-15 & $5-\mathrm{Mar}-15$ \\
\hline & & & LP INNER CASING WELDING-LOWER PART & & & 10-Feb-15 & 20-Feb-15 & 21-Feb-15 & 5-Mar-15 & 14-Mar-15 \\
\hline \multirow{2}{*}{6} & \multirow{2}{*}{ LPIC 6} & \multirow{2}{*}{ TYPE E } & LP INNER CASING WELDING-UPPERPART & \multirow{2}{*}{ PO RELEASE } & \multirow{2}{*}{ 11-Jun-15 } & 19-Feb-15 & 3-Mar-15 & 4-Mar-15 & 14-Mar-15 & 26-Mar-15 \\
\hline & & & LP INNER CASING WELDING-LOWER PART & & & 3-Mar-15 & 13-Mar-15 & 14-Mar-15 & 26-Mar-15 & 7-Apr-15 \\
\hline
\end{tabular}

\section{Gambar 5 Data Mentah Schedule Planning}

\section{Transformasi Data}

Transformasi data merupakan tahapan yang akan dilakukan setelah persiapan dan seleksi data. Pada tahap ini data mentah akan disesuaikan kedalam format yang 
diterima oleh perangkat lunak yang akan membantu melakukan pemrosesan data (Matlab). Ada dua tahapan yang akan dilakukan didalam tahapan ini, yaitu:

\section{a. Transformasi Format Data}

Pada tahap ini data mentah schedule planning tersebut dirubah pada bagian waktu proses dari setiap komponen pada masing-masing mesin kedalam bentuk satuan hari. Gambar 3.2 ini merupakan gambaran hasil transformasi tersebut secara umum.

\begin{tabular}{|c|c|c|c|c|c|c|c|c|c|c|}
\hline No. & $\begin{array}{c}\text { Project } \\
\text { Name }\end{array}$ & \begin{tabular}{|c} 
Type \\
Project
\end{tabular} & Komponen (Job) & Status PO & Planning & $\begin{array}{c}\text { Flame Cutting } \\
\text { (CNC+Sawing+ } \\
\text { Manual } \\
\text { Cutting) }\end{array}$ & $\begin{array}{c}\text { Rolling } \\
\text { (Internal \& } \\
\text { Eksternal) }\end{array}$ & $\begin{array}{l}\text { Machining } \\
\text { Small Part }\end{array}$ & $\begin{array}{l}\text { Assy Single } \\
\text { Part } \\
\text { (Welding+ } \\
\text { NDT) }\end{array}$ & $\begin{array}{l}\text { Assy Sub } \\
\text { Assy } \\
\text { (Welding+ } \\
\text { NDT) }\end{array}$ \\
\hline \multirow{4}{*}{1} & \multirow{4}{*}{ LPIC1 } & \multirow{4}{*}{ TYPE D } & LP INNER CASING WELDING-UPPER PART & \multirow{4}{*}{$\begin{array}{c}\text { PO } \\
\text { RELEASE }\end{array}$} & \multirow{4}{*}{ 23-Feb-15 } & 10 & 1 & 12 & 21 & 10 \\
\hline & & & LP INNER CASING WELDING-LOWER PART & & & 12 & 1 & 10 & 21 & 12 \\
\hline & & & DIFFUSER TS & & & 10 & 1 & 12 & 31 & 12 \\
\hline & & & DIFFUSER GS & & & 12 & 1 & 10 & 21 & 12 \\
\hline \multirow{4}{*}{2} & \multirow{4}{*}{ LPIC2 } & \multirow{4}{*}{ TYPE E } & LP INNER CASING WELDING-UPPER PART & \multirow{4}{*}{$\begin{array}{c}\text { PO } \\
\text { RELEASE }\end{array}$} & \multirow{4}{*}{ 16-Mar-15 } & 10 & 1 & 12 & 21 & 14 \\
\hline & & & \begin{tabular}{|l|} 
LP INNER CASING WELDING-LOWER PART \\
\end{tabular} & & & 12 & 1 & 14 & 21 & 13 \\
\hline & & & DIFFUSER TS & & & 10 & 1 & 12 & 35 & 13 \\
\hline & & & DIFFUSER GS & & & 12 & 1 & 10 & 25 & 13 \\
\hline \multirow{4}{*}{3} & \multirow{4}{*}{ LPIC 3} & \multirow{4}{*}{ TYPE A } & LP INNER CASING WELDING-UPPER PART & \multirow{4}{*}{$\begin{array}{c}\text { PO } \\
\text { RELEASE }\end{array}$} & \multirow{4}{*}{ 7-Apr-15 } & 14 & 1 & 11 & 21 & 12 \\
\hline & & & LP INNER CASING WELDING-LOWER PART & & & 11 & 1 & 12 & 21 & 12 \\
\hline & & & DIFFUSER TS & & & 10 & 1 & 12 & 36 & 12 \\
\hline & & & DIFFUSER GS & & & 12 & 1 & 14 & 22 & 12 \\
\hline \multirow{4}{*}{4} & \multirow{4}{*}{ LPIC 4} & \multirow{4}{*}{ TYPE E } & LP INNER CASING WELDING-UPPER PART & \multirow{4}{*}{$\begin{array}{c}\text { PO } \\
\text { RELEASE }\end{array}$} & \multirow{4}{*}{ 28-Apr-15 } & 12 & 1 & 10 & 21 & 12 \\
\hline & & & \begin{tabular}{|l|} 
LP INNER CASING WELDING-LOWER PART \\
\end{tabular} & & & 10 & 1 & 12 & 21 & 12 \\
\hline & & & DIFFUSER TS & & & 14 & 1 & 11 & 33 & 12 \\
\hline & & & DIFFUSER GS & & & 11 & 1 & 12 & 21 & 12 \\
\hline
\end{tabular}

Gambar 6 Hasil Transformasi Format Data

\section{b. Transformasi Data kedalam Matriks}

Tahapan transformasi data kedalam bentuk matriks adalah merubah data satuan hari diatas kedalam bentuk matriks dan simbol dengan tujuan mempermudah dalam proses pengolahan data dan mempermudah ketika melakukan proses pengimputan data menggunakan perangkat lunak matlab tersebut. 
Jurnal Sistem Informasi dan Informatika (SIMIKA)

Vol.1 No.1 tahun 2018

\section{Split Data}

Tahapan split data merupakan tahapan dimana data yang berasal dari transformasi matriks tersebut dikelompokan berdasarkan kelompok data yang akan diproses sesuai Schedule planning dan data yang memiliki sifat non-deterministik (tidak dapat diramalkan).

Sifat non-deterministik didalam set data ini diambil dari status purchase order (PO) project yang pada awalanya sudah ditetapkan terlebih dahulu Schedule planningnya oleh planner. Namun hingga waktu akan diproses status dari penetapan (approval) dari PO tersebut tidak berubah, oleh karena itu perlu dilakukan tindakan pengambilan keputusan mengutamakan project yang sudah memiliki status PO (PO Release) meskipun project yang memiliki status PO not-release merupakan project yang lebih dahulu direncanakan.

\section{Pengolahan Data Training}

\begin{tabular}{|c|c|c|c|c|c|c|c|c|c|c|c|c|c|c|c|c|c|c|c|c|c|}
\hline \multirow{3}{*}{\multicolumn{2}{|c|}{$\begin{array}{c}\text { Project (Job) } \\
\text { Komponen } \\
\text { Operasi }\end{array}$}} & \multicolumn{10}{|c|}{ A } & \multicolumn{10}{|c|}{ B } \\
\hline & & \multicolumn{5}{|c|}{ Al } & \multicolumn{5}{|c|}{ A2 } & \multicolumn{5}{|c|}{ B1 } & \multicolumn{5}{|c|}{ B2 } \\
\hline & & 1 & 2 & 3 & 4 & 5 & 1 & 2 & 3 & 4 & 5 & 1 & 2 & 3 & 4 & 5 & 1 & 2 & 3 & 4 & 5 \\
\hline \multirow{5}{*}{ 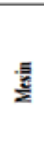 } & Mn & 10 & & & & & 12 & & & & & 10 & & & & & 12 & & & & \\
\hline & M2 & & 1 & & & & & 1 & & & & & 1 & & & & & 1 & & & \\
\hline & $\mathbf{M} 3$ & & & 12 & & & & & 10 & & & & & 12 & & & & & 14 & & \\
\hline & M4 & & & & 10 & & & & & 12 & & & & & 20 & & & & & 11 & \\
\hline & M5 & & & & & 10 & & & & & 12 & & & & & 14 & & & & & 13 \\
\hline \multicolumn{2}{|c|}{ Project (Job) } & \multicolumn{10}{|c|}{ C } & \multicolumn{10}{|c|}{ D } \\
\hline \multicolumn{2}{|c|}{ Komponen } & \multicolumn{5}{|c|}{$\mathrm{Cl}$} & \multicolumn{5}{|c|}{$\mathrm{C} 2_{2}$} & \multicolumn{5}{|c|}{ D1 } & \multicolumn{5}{|c|}{ D2 } \\
\hline \multicolumn{2}{|c|}{ Operasi } & 1 & 2 & 3 & 4 & 5 & 1 & 2 & 3 & 4 & 5 & 1 & 2 & 3 & 4 & 5 & 1 & 2 & 3 & 4 & 5 \\
\hline \multirow{5}{*}{$\frac{\sqrt{\frac{n}{z}}}{\frac{\underline{x}}{z}}$} & Mn & 14 & & & & & 11 & & & & & 12 & & & & & 10 & & & & \\
\hline & M2 & & 1 & & & & & 1 & & & & & 1 & & & & & 1 & & & \\
\hline & M3 & & & 11 & & & & & 12 & 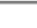 & 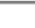 & & & 10 & & & & & 12 & & \\
\hline & M4 & & & & 12 & & & & & 10 & & & & & 12 & & & & & 10 & \\
\hline & M5 & & & & & 12 & & & & & 12 & & & & & 12 & & & & & 12 \\
\hline \multicolumn{2}{|c|}{ Project (Job) } & \multicolumn{10}{|c|}{$\mathbf{E}$} & \multicolumn{10}{|c|}{$\mathbf{F}$} \\
\hline \multicolumn{2}{|c|}{ Komponen } & \multicolumn{5}{|c|}{ E1 } & \multicolumn{5}{|c|}{ E2 } & \multicolumn{5}{|c|}{ F1 } & \multicolumn{5}{|c|}{ F2 } \\
\hline & & 1 & 2 & 3 & 4 & 5 & 1 & 2 & 3 & 4 & 5 & 1 & 2 & 3 & 4 & 5 & 1 & 2 & 3 & 4 & 5 \\
\hline & Mn & 12 & & & & & 10 & & & & & 12 & & & & & 10 & & & & \\
\hline & M2 & & 1 & & & & & 1 & & & & & 1 & & & & & 1 & & & \\
\hline ह & $\mathbf{M 3}$ & & & 10 & & & & & 12 & & & & & 10 & & & & & 12 & & \\
\hline & M4 & & & & 12 & & & & & 10 & & & & & 12 & & & & & 13 & \\
\hline & M5 & & & & & 12 & & & & & 12 & & & & & 12 & & & & & 13 \\
\hline
\end{tabular}

Gambar 7 Data Training Project LPIC 
Jurnal Sistem Informasi dan Informatika (SIMIKA)

Vol.1 No.1 tahun 2018

Tabel 1 Parameter yang Ditetapkan

\begin{tabular}{|c|c|c|c|}
\hline Paramater & Keterangan & Ketetapan & Nilai Ketetapan \\
\hline$\alpha$ & $\begin{array}{c}\text { the relative importance of } \\
\text { the trail }\end{array}$ & $\alpha \geq 0$ & $\{1,2\}$ \\
\hline$\beta$ & $\begin{array}{c}\text { the relative importance of } \\
\text { the visibility }\end{array}$ & $\beta \geq 0$ & $\{2,5\}$ \\
\hline$\rho$ & Trail persistence & $0 \leq \rho<1$ & $\{0.5,0.99\}$ \\
\hline $\mathrm{Q}$ & $\begin{array}{c}\text { a constant related to the } \\
\text { quantity of trail laid by ants }\end{array}$ & & $\{100,1000\}$ \\
\hline
\end{tabular}

\section{Hasil Pemrosesan Data}

Adapun kombinasi yang akan dilakukan penelitian $\{\alpha, \beta, \rho$, dan $Q\}$ adalah tertera pada tabel 2 dibawah ini:

Tabel 2 Kombinasi Parameter

\begin{tabular}{|c|c|c|c|c|}
\hline$\alpha$ & $\boldsymbol{\beta}$ & $\rho$ & $\mathbf{Q}$ & Kombinasi \\
\hline \multirow{8}{*}{1} & \multirow{4}{*}{2} & \multirow{2}{*}{0.5} & 100 & $\{1,2,0.5,100\}$ \\
\hline & & & 1000 & $\{1,2,0.5,1000\}$ \\
\hline & & \multirow{2}{*}{0.99} & 100 & $\{1,2,0.99,100\}$ \\
\hline & & & 1000 & $\{1,2,0.99,1000\}$ \\
\hline & \multirow{4}{*}{5} & \multirow{2}{*}{0.5} & 100 & $\{1,5,0.5,100\}$ \\
\hline & & & 1000 & $\{1,5,0.5,1000\}$ \\
\hline & & \multirow{2}{*}{0.99} & 100 & $\{1,5,0.99,100\}$ \\
\hline & & & 1000 & $\{1,5,0.99,1000\}$ \\
\hline \multirow{8}{*}{2} & \multirow{4}{*}{2} & \multirow{2}{*}{0.5} & 100 & $\{2,2,0.5,100\}$ \\
\hline & & & 1000 & $\{2,2,0.5,1000\}$ \\
\hline & & \multirow{2}{*}{0.99} & 100 & $\{2,2,0.99,100\}$ \\
\hline & & & 1000 & $\{2,2,0.99,1000\}$ \\
\hline & \multirow{4}{*}{5} & \multirow{2}{*}{0.5} & 100 & $\{2,5,0.5,100\}$ \\
\hline & & & 1000 & $\{2,5,0.5,1000\}$ \\
\hline & & \multirow{2}{*}{0.99} & 100 & $\{2,5,0.99,100\}$ \\
\hline & & & 1000 & $\{2,5,0.99,1000\}$ \\
\hline
\end{tabular}


Jurnal Sistem Informasi dan Informatika (SIMIKA)

Vol.1 No.1 tahun 2018

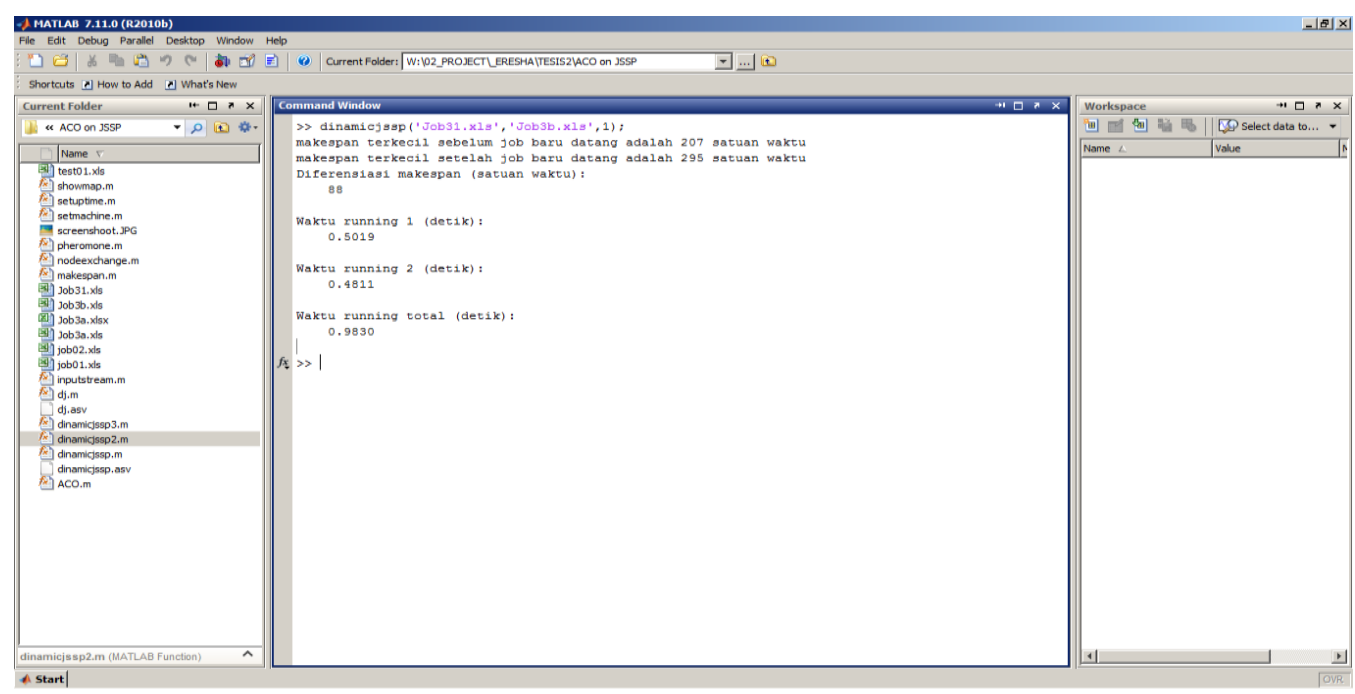

Gambar 8 Total Makespan Time

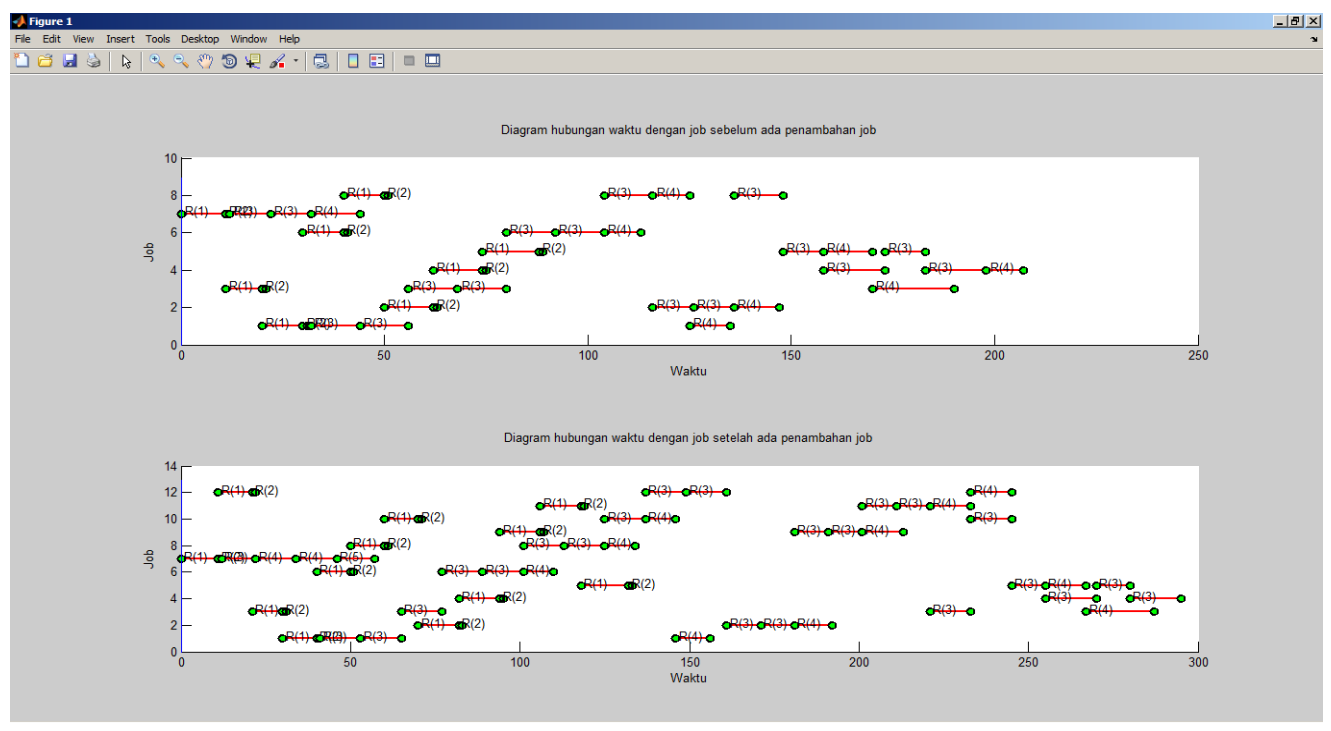

Gambar 9 Diagram Hubungan Waktu Dengan Job Sebelum dan Sesudah Penambahan Job 


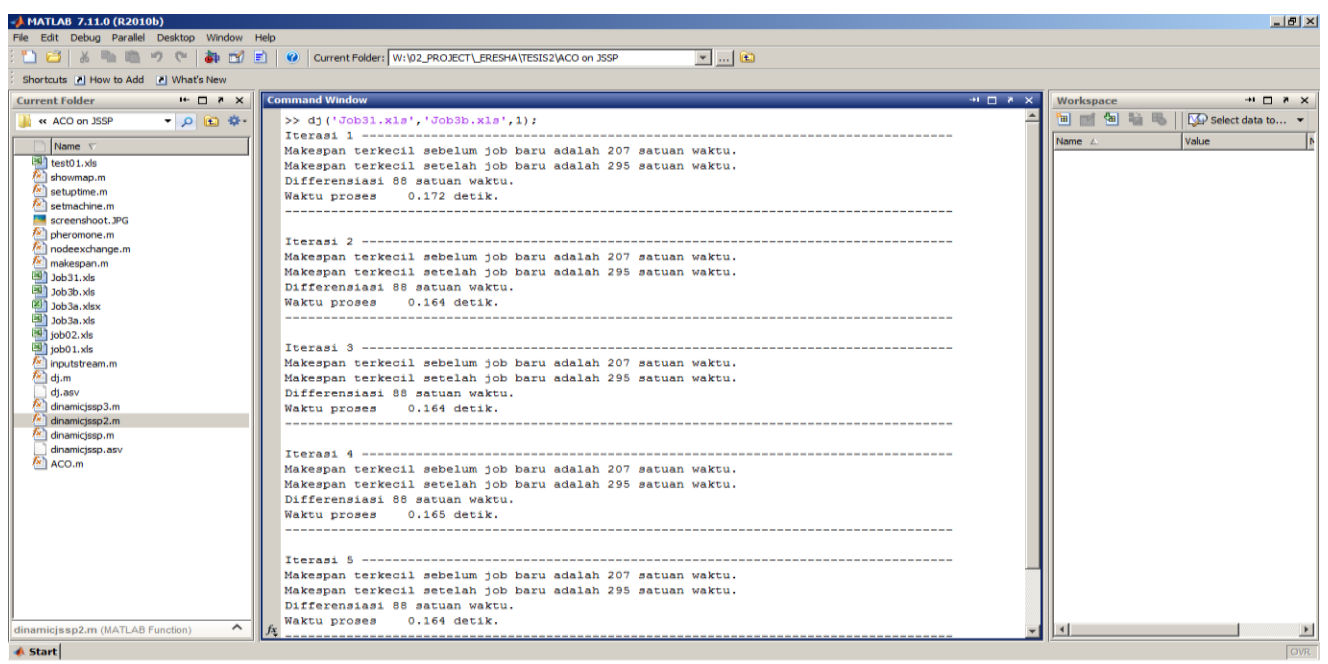

Gambar 10 Output Waktu Rata - Rata Proses

Tabel 3 Perbandingan Hasil Makespan Time dari Berbagai Paramater

\begin{tabular}{|c|c|c|c|c|c|c|c|c|c|c|c|c|c|c|}
\hline \multirow[b]{2}{*}{ No. } & \multirow[b]{2}{*}{$a$} & \multirow[b]{2}{*}{$\beta$} & \multirow[b]{2}{*}{$\rho$} & \multirow[b]{2}{*}{ Q } & \multirow[b]{2}{*}{ Kombinasi } & \multicolumn{2}{|c|}{ Result } & \multirow{2}{*}{$\begin{array}{c}\text { Diferensiasi } \\
\text { makespan } \\
\text { (Hari) }\end{array}$} & \multicolumn{5}{|c|}{ Waktu Proses } & \multirow{2}{*}{$\begin{array}{r}\text { Waktu } \\
\text { Proses } \\
\text { Rata-rata }\end{array}$} \\
\hline & & & & & & $\begin{array}{l}\text { Makespantime } \\
\text { Sebelum } \\
\text { Penambahan } \\
\text { Job (Hari) }\end{array}$ & $\begin{array}{l}\text { Makespantime } \\
\text { Setelah } \\
\text { Penambahan } \\
\text { Job (Hari) }\end{array}$ & & $\begin{array}{c}\text { Iterasi l } 1 \\
\text { (Detik) }\end{array}$ & $\begin{array}{c}\text { Iterasi } 2 \\
\text { (Detik) }\end{array}$ & $\begin{array}{c}\text { Iterasi } 3 \\
\text { (Detik) }\end{array}$ & $\begin{array}{c}\text { Iterasi } 4 \\
\text { (Detik) }\end{array}$ & $\begin{array}{c}\text { Iterasi } 5 \\
\text { (Detik) }\end{array}$ & \\
\hline 1 & \multirow{8}{*}{1} & \multirow{4}{*}{2} & \multirow{2}{*}{0.5} & 100 & $\{1,2,0.5,100\}$ & 207 & 295 & 88 & 0.185 & 0.163 & 0.167 & 0.164 & 0.165 & 0.169 \\
\hline 2 & & & & 1000 & $\{1,2,0.5,1000\}$ & 207 & 295 & 88 & 0.177 & 0.163 & 0.165 & 0.166 & 0.162 & 0.167 \\
\hline 3 & & & \multirow{2}{*}{0.99} & 100 & $\{1,2,0.99,100\}$ & 207 & 295 & 88 & 0.180 & 0.163 & 0.163 & 0.164 & 0.169 & 0.168 \\
\hline 4 & & & & 1000 & $\{1,2,0.99,1000\}$ & 207 & 295 & 88 & 0.184 & 0.163 & 0.163 & 0.166 & 0.162 & 0.168 \\
\hline 5 & & \multirow{4}{*}{5} & \multirow{2}{*}{0.5} & 100 & $\{1,5,0.5,100\}$ & 207 & 295 & 88 & 0.180 & 0.162 & 0.165 & 0.174 & 0.167 & 0.170 \\
\hline 6 & & & & 1000 & $\{1,5,0.5,1000\}$ & 207 & 295 & 88 & 0.186 & 0.163 & 0.161 & 0.161 & 0.161 & 0.166 \\
\hline 7 & & & \multirow{2}{*}{0.99} & 100 & $\{1,5,0.99,100\}$ & 207 & 295 & 88 & 0.182 & 0.164 & 0.164 & 0.166 & 0.168 & 0.169 \\
\hline 8 & & & & 1000 & $\{1,5,0.99,1000\}$ & 207 & 295 & 88 & 0.184 & 0.171 & 0.164 & 0.177 & 0.172 & 0.174 \\
\hline 9 & \multirow{8}{*}{2} & \multirow{4}{*}{2} & \multirow{2}{*}{0.5} & 100 & $\{2,2,0.5,100\}$ & 207 & 295 & 88 & 0.175 & 0.163 & 0.162 & 0.163 & 0.167 & 0.166 \\
\hline 10 & & & & 1000 & $\{2,2,0.5,1000\}$ & 207 & 295 & 88 & 0.181 & 0.162 & 0.167 & 0.170 & 0.165 & 0.169 \\
\hline 11 & & & \multirow{2}{*}{0.99} & 100 & $\{2,2,0.99,100\}$ & 207 & 295 & 88 & 0.177 & 0.162 & 0.162 & 0.163 & 0.162 & 0.165 \\
\hline 12 & & & & 1000 & $\{2,2,0.99,1000\}$ & 207 & 295 & 88 & 0.178 & 0.163 & 0.163 & 0.163 & 0.162 & 0.166 \\
\hline 13 & & \multirow{4}{*}{5} & \multirow{2}{*}{0.5} & 100 & $\{2,5,0.5,100\}$ & 207 & 295 & 88 & 0.183 & 0.167 & 0.164 & 0.163 & 0.163 & 0.168 \\
\hline 14 & & & & 1000 & $\{2,5,0.5,1000\}$ & 207 & 295 & 88 & 0.187 & 0.163 & 0.166 & 0.163 & 0.162 & 0.168 \\
\hline 15 & & & \multirow{2}{*}{0.99} & 100 & $\{2,5,0.99,100\}$ & 207 & 295 & 88 & 0.179 & 0.168 & 0.164 & 0.164 & 0.165 & 0.168 \\
\hline 16 & & & & 1000 & $\{2,5,0.99,1000\}$ & 207 & 295 & 88 & 0.185 & 0.170 & 0.164 & 0.176 & 0.164 & 0.172 \\
\hline
\end{tabular}




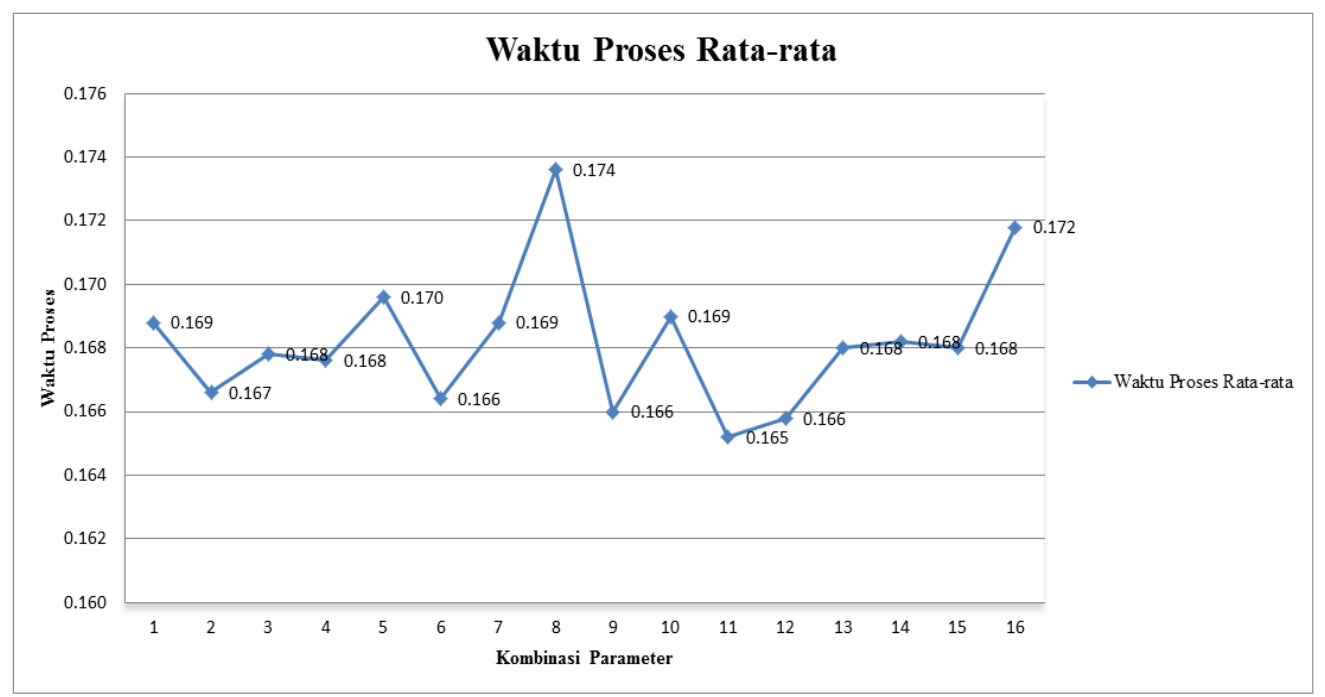

Gambar 11 Grafik Waktu Proses Rata-rata

Dari hasil menunjukan bahwa makespan time terkecil sebelum job baru datang adalah 207 hari satuan waktu, sedangkan makespan time terkecil setelah job baru datang adalah 295 hari satuan waktu untuk data dengan menggunakan nilai ketetapan $\{\alpha, \beta, \rho$, dan $\mathrm{Q}\}=\{1,2,0.5,100\}$. Dengan ini menjelaskan bahwa untuk menyelesaikan 4 job (8 komponen) dengan jumlah mesin sebanyak 5 mesin maka makespan time terkecil yang dibutuhkan adalah selama 207 hari. Namun apabila kedatangan job yang sifatnya non-deterministic maka akan melakukan proses re-schedull penjadwalan yang sudah diramalkan, oleh karena itu akan muncul perubahan waktu yang lebih lama untuk menyelesaikan semua job termasuk jobnon-deterministic tersebut sebesar 295 hari (2 job non deterministic). 
Jurnal Sistem Informasi dan Informatika (SIMIKA)

Vol.1 No.1 tahun 2018

\section{Pengolahan Data Testing}

\begin{tabular}{|c|c|c|c|c|c|c|c|c|c|c|c|c|c|c|c|c|c|c|c|c|c|}
\hline \multirow{3}{*}{\multicolumn{2}{|c|}{$\begin{array}{c}\text { Project (Job) } \\
\text { Komponen } \\
\text { Operasi }\end{array}$}} & \multicolumn{10}{|c|}{ O } & \multicolumn{10}{|c|}{$\mathbf{P}$} \\
\hline & & \multicolumn{5}{|c|}{ O1 } & \multicolumn{5}{|c|}{$\mathrm{O} 2$} & \multicolumn{5}{|c|}{ P1 } & \multicolumn{5}{|c|}{$\mathrm{P} 2$} \\
\hline & & 1 & 2 & 3 & 4 & 5 & 1 & 2 & 3 & 4 & 5 & 1 & 2 & 3 & 4 & 5 & 1 & 2 & 3 & 4 & 5 \\
\hline \multirow{5}{*}{ 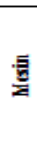 } & M1 & 10 & & & & & 14 & & & & & 12 & & & & & 14 & & & & \\
\hline & M2 & & 1 & & & & & 1 & & & & & 1 & & & & & 1 & & & \\
\hline & M3 & & & 14 & & & & & 12 & & & & & 14 & & & & & 10 & & \\
\hline & M/4 & & & & 12 & & & & & 13 & & & & & 20 & & & & & 11 & \\
\hline & M5 & & & & & 11 & & & & & 10 & & & & & 11 & & & & & 10 \\
\hline
\end{tabular}

\begin{tabular}{|c|c|c|c|c|c|c|c|c|c|c|c|c|c|c|c|c|c|c|c|c|c|}
\hline \multirow{2}{*}{\multicolumn{2}{|c|}{$\begin{array}{l}\text { Project (Job) } \\
\text { Komponen }\end{array}$}} & \multicolumn{10}{|c|}{$\mathbf{Q}$} & \multicolumn{10}{|c|}{$\mathbf{R}$} \\
\hline & & \multicolumn{5}{|c|}{ Q1 } & \multicolumn{5}{|c|}{ Q2 } & \multicolumn{5}{|c|}{ Rl } & \multicolumn{5}{|c|}{ R2 } \\
\hline & & 1 & 2 & 3 & 4 & 5 & 1 & 2 & 3 & 4 & 5 & 1 & 2 & 3 & 4 & 5 & 1 & 2 & 3 & 4 & 5 \\
\hline \multirow{5}{*}{ 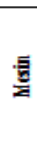 } & M1 & 12 & & & & & 12 & & & & & 12 & & & & & 12 & & & & \\
\hline & M/2 & & 1 & & & & & 1 & & & & & 1 & & & & & 1 & & & \\
\hline & M3 & & & 12 & & & & & 10 & & & & & 12 & & & & & 10 & & \\
\hline & $\mathbf{M} / 4$ & & & & 10 & & & & & 11 & & & & & 10 & & & & & 14 & \\
\hline & M5 & & & & & 11 & & & & & 10 & & & & & 11 & & & & & 10 \\
\hline
\end{tabular}

\begin{tabular}{|c|c|c|c|c|c|c|c|c|c|c|c|}
\hline \multirow{3}{*}{\multicolumn{2}{|c|}{$\begin{array}{c}\text { Project (Job) } \\
\text { Komponen } \\
\text { Operasi }\end{array}$}} & \multicolumn{10}{|c|}{ S } \\
\hline & & \multicolumn{5}{|c|}{ S1 } & \multicolumn{5}{|c|}{ S2 } \\
\hline & & 1 & 2 & 3 & 4 & 5 & 1 & 2 & 3 & 4 & 5 \\
\hline \multirow{5}{*}{ 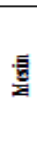 } & M1 & 12 & & & & & 15 & & & & \\
\hline & M2 & & 1 & & & & & 1 & & & \\
\hline & $\mathrm{M} 3$ & & & 15 & & & & & 13 & & \\
\hline & MA & & & & 13 & & & & & 9 & \\
\hline & M5 & & & & & 11 & & & & & 10 \\
\hline
\end{tabular}

\begin{tabular}{|c|c|c|c|c|c|c|c|c|c|c|c|c|c|c|c|c|c|c|c|c|c|}
\hline \multirow{3}{*}{\multicolumn{2}{|c|}{$\begin{array}{c}\text { Project (Job) } \\
\text { Komponen } \\
\text { Operasi }\end{array}$}} & \multicolumn{10}{|c|}{$\mathbf{T}$} & \multicolumn{10}{|c|}{$u$} \\
\hline & & \multicolumn{5}{|c|}{ T1 } & \multicolumn{5}{|c|}{ T2 } & \multicolumn{5}{|c|}{ U1 } & \multicolumn{5}{|c|}{ U2 } \\
\hline & & 1 & 2 & 3 & 4 & 5 & 1 & 2 & 3 & 4 & 5 & 1 & 2 & 3 & 4 & 5 & 1 & 2 & 3 & 4 & 5 \\
\hline \multirow{5}{*}{ 氮 } & M1 & 13 & & & & & 10 & & & & & 12 & & & & & 13 & & & & \\
\hline & M2 & & 1 & & & & & 1 & & & & & 1 & & & & & 1 & & & \\
\hline & M3 & & & 10 & & & & & 12 & & & & & 13 & & & & & 12 & & \\
\hline & M/4 & & & & 12 & & & & & 12 & & & & & 12 & & & & & 12 & \\
\hline & M5 & & & & & 11 & & & & & 10 & & & & & 11 & & & & & 10 \\
\hline
\end{tabular}

Gambar 12 Data Testing Project LPIC

Tabel 4 Parameter Testing yang Ditetapkan

\begin{tabular}{|c|c|c|c|}
\hline Paramater & Keterangan & Ketetapan & Nilai Ketetapan \\
\hline$\alpha$ & $\begin{array}{c}\text { the relative importance of } \\
\text { the trail }\end{array}$ & $\alpha \geq 0$ & $\{2\}$ \\
\hline$\beta$ & $\begin{array}{c}\text { the relative importance of } \\
\text { the visibility }\end{array}$ & $\beta \geq 0$ & $\{2\}$ \\
\hline$\rho$ & Trail persistence & $0 \leq \rho<1$ & $\{0.99\}$ \\
\hline $\mathrm{Q}$ & $\begin{array}{c}\text { a constant related to the } \\
\text { quantity of trail laid by ants }\end{array}$ & & $\{100\}$ \\
\hline
\end{tabular}


Jurnal Sistem Informasi dan Informatika (SIMIKA)

Vol.1 No.1 tahun 2018

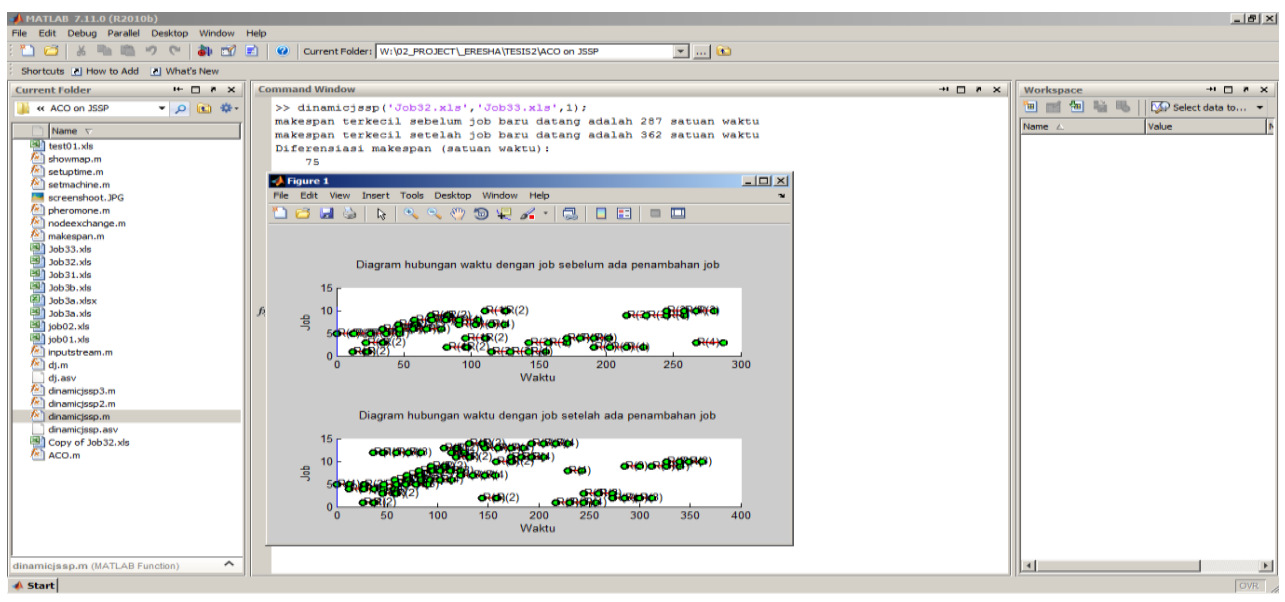

Gambar 13 Output Pengolahan Data Testing

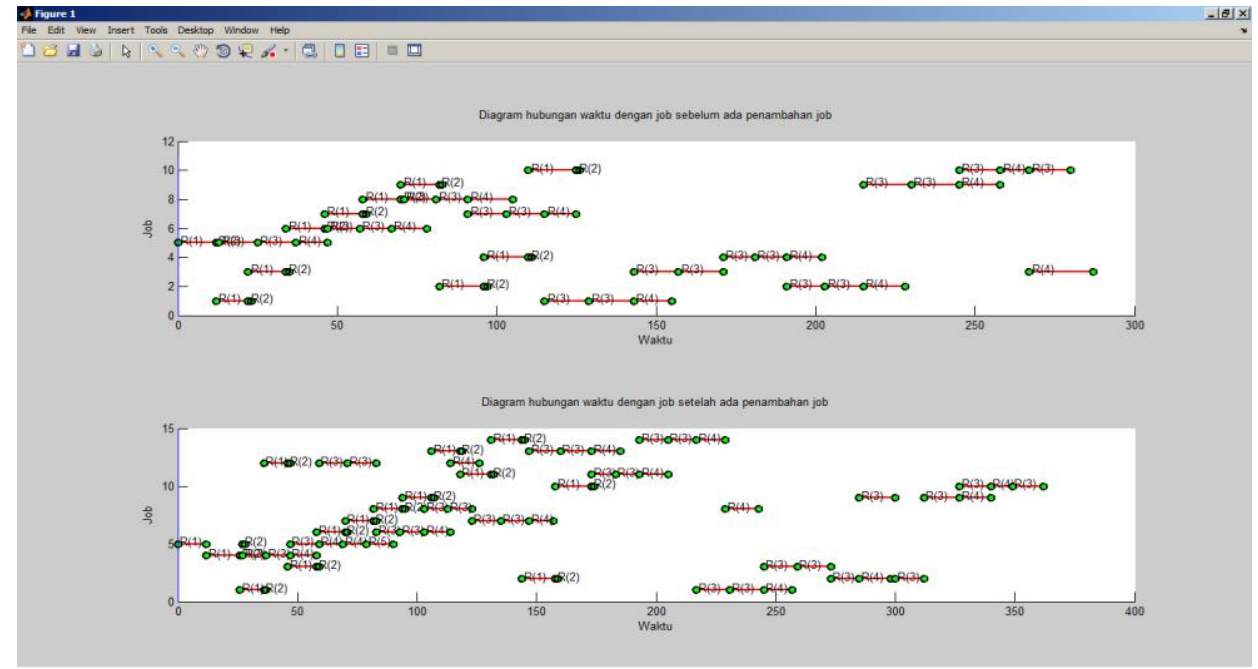

Gambar 14 Diagram Hubungan Waktu Dengan Job Sebelum Dan Sesudah Penambahan Job 


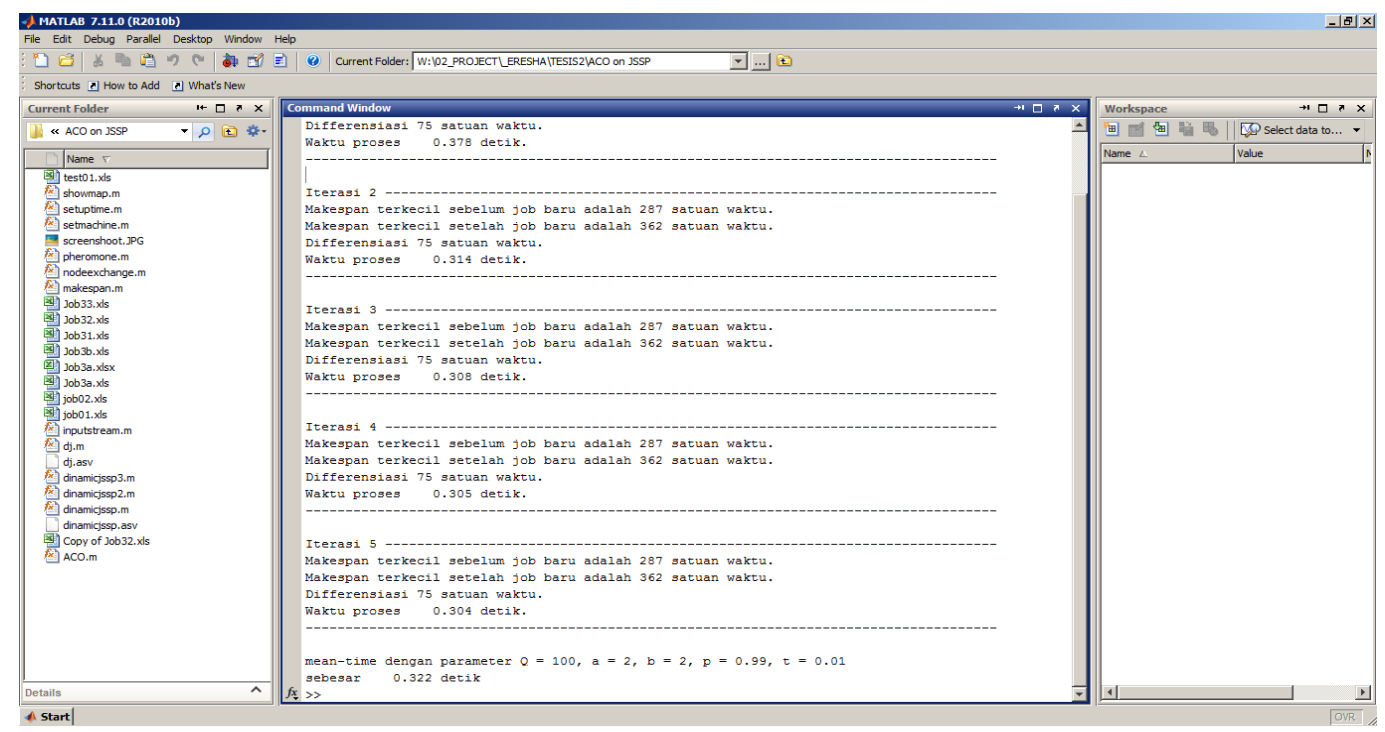

\section{Gambar 15 Output Waktu Rata - Rata Proses}

Dari hasil menunjukan bahwa makespan time terkecil untuk pengolahan data testing sebelum job baru datang adalah 287 hari satuan waktu, sedangkan makespan time terkecil setelah job baru datang adalah 362 hari satuan waktu untuk data dengan menggunakan nilai ketetapan $\{\alpha, \beta, \rho$, dan $\mathrm{Q}\}=\{2,2,0,99,100\}$. Dengan ini menjelaskan bahwa untuk menyelesaikan 5 job (10 Komponen) dengan jumlah mesin sebanyak 5 mesin maka makespan time terkecil yang dibutuhkan adalah selama 287 hari. Namun apabila kedatangan job yang sifatnya non-deterministic (2 job) maka akan melakukan proses re-schedull penjadwalan yang sudah diramalkan, oleh karena itu akan muncul perubahan waktu yang lebih lama untuk menyelesaikan semua job termasuk jobnon-deterministic tersebut sebesar 362 hari.

\section{Kesimpulan}

Adapun kesimpulan yang didapatkan berdasarkan pengolahan data testing untuk penerapan Ant Colony Optimization (ACO) berjenis Ant System (AS) pada Job Shop Scheduling Problem (JSSP) di PT. Siemens Indonesia dengan menggunakan parameter terbaik $\{\alpha, \beta, \rho$, dan $\mathrm{Q}\}=\{2,2,0,99,100\}$ adanya perbedaan antara waktu penyelesaian proses produksi actual yang ditetapkan oleh planner dengan waktu proses produksi yang menggunakan algoritma ACO. Waktu proses actual yang 
dibutuhkan adalah 1 bulan atau +/- 37 hari untuk penyelesaian 1 komponenoleh karena itu jika mengerjakan 5 project (10 komponen) dibutuhkan waktu selama +/370 hari, sedangkan didalam data testing dengan jumlah 5 project (10 komponen) waktu yang dibutuhkan adalah selama 287 hari. Ketika kedatangan job yang bersifat non - deterministic sebanyak 2 project/job (4 komponen) dibutuhkan waktu selama 362 hari sedangkan secara actual dibutuhkan waktu untuk pengerjaan 7 project/job (14 komponen) adalah selama +/- 517 hari. Hal ini menunjukan bahwa dengan menerapkan Algoritma ACO didalam JSSP dapat menghemat waktu selama +/- 155 hari.

\section{Daftar Pustaka}

Al Salami, N. M. (2009). Ant Colony Optimization Algorithm. UbiCC Journal, Volume 4, Number 3, 823-826.

Anamisa, D. R., \& Djunaidy, A. (2014). Penyelesaian Penjadwalan Mata Kuliah Menggunakan Hibridisasi Algoritma Genetika dan Algoritma Koloni Semut. JUTI, Volume 12, Nomor 1, 15-20.

Aprilius, W., Augustino, L., \& M. H., O. Y. (2013). Implementasi Algoritma MAX-MIN Ant System pada Penjadwalan Mata Kuliah. ULTIMATICS, Vol. V, No. 2, ISSN 20854552, 48-53.

Ariesta, Y. (2012). Penerapan Ant Colony System Pada Vehicle Routing Problem Untuk Menentukan Rute Distribusi Terpendek. Jakarta: Jurusan Teknik Industri, Fakultas Teknologi Industri, Universitas Trisakti.

Astuti, M. (2013). Studi Penjadwalan Job Shop untuk Meminimalkan Waktu Keseluruhan Menggunakan Pendekatan Algoritma Artificial Immune System. Yogyakarta: Volume $\mathrm{V}$, Nomor 1.

Çalis, B., \& Bulkan, S. (2013). A research survey: review of AI solution strategies of job shop scheduling problem. Journal of Intelligent Manufacturing (DOI 10.1007/s10845013-0837-8).

Dorigo, M. (1996). The Ant System: Optimization by a Colony Of Cooperating Agents. IEEE Transactions on Systems, Man, and Cybernetics-Part B, Vol.26, No.1, 1996, pp.1-13, $1-26$.

Dorigo, M., Di Caro, G., \& Gambardella, L. (1999). Ant Algorithms for Discrete Optimization.

Flórez, E., Gómez, W., \& Bautista, M. (2013). An Ant Colony Optimization Algorithm For Job Shop Scheduling Problem. International Journal of Artificial Intelligence \& Applications (IJAIA), Vol. 4, No. 4, 53-66.

Jones, A., \& Rabelo, L. (1998). Survey of Job Shop Scheduling Techniques.

Laksono, A. (2009). Algoritma Ant Colony Optimization (ACO) Untuk Menyelesaikan Traveling Salesman Problem (TSP). Semarang: Program Studi Matematika Jurusan Matematika, Fakultas MIPA, Universitas Diponegoro. 
Omkumar, M., \& Shahabudeen, P. (n.d.). Ant Colony Optimization for Multilevel Assembly Job Shop Scheduling. The International Journal of Applied Management and Technology, Vol 6, Num 1 (IJAMT), 127-152.

Rajendran, C., \& Ziegler, H. (2004). Ant-colony algorithms for permutation flowshop scheduling to minimize makespan/total flowtime of jobs. European Journal of Operational Research 155 (2004), Elsevier, 426-438.

Ventresca, M., \& Ombuki, B. (2004). Ant Colony Optimization for Job Shop Scheduling Problem. St. Catharines, Ontario, Canada L2S 3A1: Brock University, Department of Computer Science.

Zhang, S., Wong, T., Zhang, L., \& Wan, S. (n.d.). A two-stage approach based on Ant Colony Optimization Algorithm for Integrated Process Planning and Scheduling. Proceedings of the 41 st International Conference on Computers \& Industrial Engineering (pp. 804-809). Pokfulam Road, Hong Kong: The University of Hong Kong.

Zukhri, Z., \& Alhakim, S. (2004). Algoritma Semut Pada Penjadwalan Produksi Job Shop. Media Informatika, Vol. 2, No. 2, ISSN: 0854-4743, 75-81. 